\title{
The pretence in education of people with profound intellectual and multiple disabilities
}

\section{KEYWORDS}

the pretence, phenomenon of the "empty minutes", the person with profound intellectual and multiple disabilities, the remedial activities

\begin{abstract}
Danuta Kopeć, The pretence in the education of the people with profound intellectual and multiple disabilities. Culture - Society - Education no. 2(18) 2020, Poznań 2020, pp. 99-113, Adam Mickiewicz University Press. ISSN 2300-0422. DOI 10.14746/kse.2020.18.4.2.
\end{abstract}

The phenomenon of pretence in the Polish educational system of the person with profound intellectual and multiple disabilities (PIMD) will be analized in the context of sociological concept of pretence by Jan Lutynski (1990). The subject of the study was the educational reality of the person with PIMD. Two main questions were formulated. What is the educational reality of the person with PIMD in the micro- and macrosystem context? What is happening in this educational reality? The study was conducted in interpretative paradigm based on quantitative research model using instrumental group case study. The subjects of the study were the people with PIMD (15) and school staff (57). During the study participant observertion, quantitaive deepened interview were used. The symptoms of pretence in education of the person with PIMD on the macrosystem level were visible in the form of inconsistencies in the legal acts regulating the course of education. On the microsystem level the manifestation of the pretence was the phenomenon of the "empty minutes" (i.e. time at school not used for the benefit of the person's development). The results of the study on the macrosystem level suggest lack of the transparency of the legal acts. On the microsystem level the need of developing applicable standards in education of the people with PIMD. 


\section{Introduction}

The phenomenon of pretence in education has been discussed by many researchers dealing with the issues of education, especially special education (cf. Kwiecinski, 1995; Dudzikowa, 2004; Zakrzewska-Manterys, 2010; Dudzikowa, 2013; Parys, 2014). Katarzyna Parys (2014) presented a very interesting analysis of the phenomenon of pretence in education of students with disabilities. In my opinion, this is the first analysis of the phenomenon of pretence in education of people with disabilities, including intellectual disabilities (2014: 29-55). The researcher analyzes the phenomenon of pretence in education of people with disabilities in the context of the sociological concept of Jan Lutynski, created in the 1970s (1990: 107, cit. Parys, 2014), which she implemented in the area of special education. According to Lutynski, "pretend actions include all activities whose actual course or direct goal are different than they appear to be" (1990: 107, cit. Parys, 2014: 30). Lutynski distinguishes four mechanisms leading to the phenomenon of pretence in education. They are as follows:

- organizational and decision-making mechanism based on confirming and adopting decisions that have been imposed contrary to the applicable rules;

- axiological mechanism characterized by actions aimed at confirming acceptance and realization of values that are not systematically implemented, despite being recognized;

- mechanism of obligatory execution of "unrealistic" regulations, manifested as the performance of impossible tasks or tasks that are useless due to their actual purpose;

- "allegedly pragmatic" mechanism, based on provoking an action that does not lead to solving difficulties, but is intended merely to confirm the interest of those responsible for solving difficulties; this mechanism is exemplified by situations in which a specific social group reports a problem that requires a solution, which decision-makers cannot or, for reasons of their own, do not want to resolve (cit. Parys, 2014: 32).

The mechanisms often coexist, complement each other and trigger certain pretend actions. Researchers of the educational pretence pay attention to its dynamic nature (cf. Dudzikowa, 2004, 2013; Parys, 2014). Importantly, the phenomenon of pretence does not show a tendency to self-extinguishing, on the contrary - one pretend action generates another, as a result we talk about a self-propelling spiral of pretence (Parys, 2014). 
The aim of the article is to describe the phenomenon of pretence in education of people with profound intellectual and multiple disabilities (PMID) ${ }^{1}$. There are two motives underlying the research exploration of pretence in education of people with PMID. The first one is related to the relatively short presence of these students in the Polish education system compared to people with mild, moderate and severe intellectual disabilities and other disabilities ${ }^{2}$. The essence of the second motive is the fact that a person with PMID, due to co-existing disabilities which almost always pose a threat to life, is a very demanding beneficiary of the education system. This fact may also facilitate the phenomenon of pretence in education of these people.

My elaboration on the phenomenon of pretence in education of people with PMID deals with the problem in general education, education of people with disabilities and education of PMID students.

\section{The phenomenon of pretence in general education and education of people with disabilities}

Although the issue of pretence in education of students attending general schools is not the subject of my considerations, a better understanding of the problem of pretence in education of people with intellectual disabilities requires quoting the results of the research project conducted by Kwiecinski, an unquestionable precursor of the issue of pretence raised by the researcher (Kwiecinski, 1995). The

${ }^{1}$ In the text, I adopt the DSM-5 definition of intellectual disability as binding (Diagnostic criteria taken from DSM-5. Desk Reference, Wroclaw, 2016). In the text on profound intellectual disability, I use the term that is recommended by the International Association for the Scientific Study of Intellectual and Developmental Disabilities (IASSID). During the last IASSID International Congress (Glasgow 6-9/08/2019), a separate section was created which throughout the entire duration of the meeting discussed the issues of a person with profound intellectual and multiple disabilities, taking into account the temporal context of life, i.e. childhood, adulthood and late adulthood in the context of related developmental tasks.

${ }^{2}$ For the first time the term of a person with profound intellectual disability appeared in the Polish education system in 1997 („Journal of Laws” 1997, no. 14, item 76: Regulation of the Minister of National Education of $30^{\text {th }}$ January 1997 on the principles of organizing remedial classes for children and adolescents with profound intellectual disability). Currently, education of people with profound intellectual disability is regulated by the „Journal of Laws” 2013, item 529 (Regulation of the Minister of National Education of $23^{\text {rd }}$ April 2013 on the conditions and manner of organizing remedial classes for children and adolescents with profound intellectual disability). The Convention on the Rights of Persons with Disabilities („Journal of Laws”, 2012, item 1169, art. 24) deals with education of people with disabilities, including PMID. 
research project was carried out in the interpretative paradigm with the use of a qualitative research model. The analysis included the structure and the way of using 100 lessons in a typical primary school, in a group of eighth-grade pupils, using covert participant observation conducted by the student who was very well prepared to follow the observation protocol in terms of reliability, accuracy, clarity and minimal entanglement with facts, attitudes and emotions (Kwiecinski, 1995: 97). The study revealed that 24,4 minutes (out of every 45 minutes) of an average lesson were somehow organized by teachers, while 5,5 minutes were used by teachers in a way that was useful for the student (Kwiecinski, 1995: 97). Therefore, in a total of 100 lessons, only 12,2\% of time can be considered valuable (Kwiecinski, 1995: 96-122). The research showed that "school is an organized waste of time and blockade of the development" (Kwiecinski, 1995: 97).

Because the research project was carried out in the interpretative paradigm, we should remember that the results relate to the school in which the project was conducted and where the lessons have been observed.

However, according to Kwiecinski, it can be hypothesized that this could be the case in any school with regard to students who expect intensive mental work (Kwiecinski, 1995). Nevertheless, we ought to remember that the frameworks of the theory of pretence created on the basis of the research results are of an individual nature, and in no way entitle us to make any generalizations (Rubacha, 2008: 329; Kubinowski, 2010; Stake, 2009: 623; Yin, 2015). Still, they can be useful for further theoretical considerations on the phenomenon of pretence and can be applied in further research projects.

This case study inclines us to raise a question what is education of a disabled pupil in a special school? Does the phenomenon of pretence also occur in special schools?

The analysis of the phenomenon of pretence in education of students with disabilities carried out by Katarzyna Parys to some extent answers these questions (2014: 29-53). This is the first analysis of the phenomenon of pretence in education of people with disabilities.

Referring to the literature reports, Parys presents the examples of pretend activities in the area of education (2014: 33). I will mention just those which, in my opinion, also apply to education of people with profound intellectual disability, including:

- purely symbolic introduction of educational changes, implementing new rituals in place of the old ones and using new slogans merely symbolizing the expected changes;

- pretending cognitive activity, critical thinking and creativity in educational activities; 
- implementation of the pretend idea of the comprehensive development of the pupil;

- work at school as an illusion, training the ability to avoid work which leads to the intended effects (Parys, 2014: 33).

In the context of the Polish education system for people with disabilities, the researcher identifies pretence in the following areas: integrated and inclusive education, the method of financing special education, supplementary education in grammar schools for students with intellectual disabilities, and textbook offer for students with disabilities (Parys, 2014: 34-49).

A very critical assessment of education of people with moderate and severe intellectual disabilities made by Elzbieta Zakrzewska-Manterys is worth quoting here (2010). Although the researcher does not directly indicates the phenomenon of pretence in education of people with intellectual disabilities, we can suspect it based on the description of education of people with moderate and severe intellectual disability.

Zakrzewska-Manterys refers to the concept of Pierre Bourdieu (2006), who like Emil Durkheim (2006), saw in pedagogy the key to the reproduction of social systems (2010). Referring to the conceptual categories, Bourdieu (2006) proves that "special education and a special school created based on its assumptions, imitate the school system in a mechanical and completely pointless manner" (2010: 165). According to the researcher, the system of special education functions "as if" it was similar to the general system, but just "slightly simpler" (2010: 165).

The assessment of the school for people with moderate and severe intellectual disability made by Zakrzewska-Manterys is very critical. In her opinion, such a school is "a scene made of papier mache, the scene on which actors play the school in various ways, but to no avail" (2010: 166), it is "a blown egg, an empty structure surrounding a void" (Zakrzewska-Manterys, 2010: 167). According to the researcher, a secret about a special school kept under wraps is that "this school does not prepare for life [...]. A special school can be a protective and cultural institution, a forum for social meetings, a place of spending useful time, where some school techniques are taught and knowledge is gained. This is a lot, but still not enough to call a special school an educational institution (emphasis added) [...]". Because in fact special schools teach pupils "how to be a competent, mentally retarded member of society” (Zakrzewska-Manterys, 2010: 168)

\footnotetext{
${ }^{3}$ I admit that as a special educator I very much resonate with such a critical description of the educational reality of a special school. Undoubtedly, this situation motivates to undertake research projects, the results of which would show a real picture of a school for people with moderate and severe intellectual disabilities in the context of the educational offer. The research project on nor-
} 


\section{The phenomenon of pretence in education of people with profound intellectual and multiple disabilities}

What is the phenomenon of pretence in education of people with profound intellectual and multiple disabilities? What is its specificity?

Before I try to answer these questions, I will shortly characterize the research project on the educational reality of a person with profound intellectual disability. Although the analysis of the phenomenon of pretence was not the aim of my study, during the implementation of the project I encountered some data which indicated the existence of the problem (Kopec, 2013).

The subject of the research project ${ }^{4}$ was to describe the educational reality of a person with profound intellectual and multiple disability, which in my opinion, was an individual space in the Polish education system, guaranteed by legal acts, and including the processes related to education, care and therapy. Two questions were crucial:

- What is the educational reality of a person with profound intellectual and multiple disability in the context of the microsystem, mesosystem, exosystem, macrosystem and chronosystem?

- What happens in the educational reality of a person with profound intellectual and multiple disability on the level of microsystem, mesosystem, exosystem, macrosystem and chronosystem?

The research ${ }^{5}$, which included empirical material, was carried out in the interpretative paradigm with the use of a qualitative research model. The subjects of the study were:

malization of the social environment of people with intellectual disabilities carried out by Amadeusz Krause, Sylwia Nosarzewska and Agnieszka Zyta in 2007/2008 is worth mentioning here (Krause, Zyta, Nosarzewska, 2010). The project was conducted in the Warmian-Masurian Voivodeship, which is characterized by a high percentage of unemployment and a high incidence of disability. The research was carried out using the quantitative and qualitative model (diagnostic survey, biographical and narrative interview). A stratified-random selection of the research sample was used; the study involved 128 people (including 26 subjects with mild intellectual disability). The results showed that the subjects' problems originate in their educational past, regardless of the educational path, i.e. being a student of a special school or an integrated school (Krause, Zyta, Nosarzewska, 2010: 172-173). The authors noticed that a person with intellectual disability is perceived as the one who "constantly needs help, is dependent, unable to make autonomous choices, has limited subjectivity and decision-making abilities" (Krause, Zyta, Nosarzewska, 2010: 180).

${ }^{4}$ A detailed description of the research project is presented in the section: The (non)educational reality of a person with profound intellectual disability. Collective instrumental case study, 2013, Kopec.

5 The research project was conducted from April 2010 to November 2011. Referring to my personal experience as a student internship tutor in remedial departments for people with profound 
- people with profound intellectual and multiple disabilities - participants of remedial classes (15) - participant observation; I accompanied pupils during participant observation throughout the remedial classes, from the moment they left their family home until they returned there;

- all school employees who entered into any relationship with the research subjects due to their professional role: school headmaster (5 people), teachers running remedial classes (24 people) and those responsible for motor improvement of students with profound intellectual disability as part of remedial classes (6 people), day-room teachers (10 people) and helpers (12 people); I conducted a partially problem-focused qualitative interview. I am aware that my research project, the core of which was a collective instrumental case study, was aimed at creating a unitary theory of reality in the broadly understood educational reality of a person with profound intellectual disability (Kopec, 2013).

In my opinion, two mechanisms mentioned by Parys are the root of the phenomenon of pretence in education of persons with profound intellectual and multiple disabilities (2014), i.e. axiological ${ }^{6}$ mechanism and allegedly pragmatic mechanism (Parys, 2014: 32). I will present the signs of the phenomenon of pretence in education of a person with profound intellectual and multiple disability only on the level of microsystem ${ }^{7}$ understood in accordance with the ecological systemic

intellectual and multiple disabilities, I observe the need to conduct a research project to examine the phenomenon of pretence in education of this group of people. When analyzing the documentation of the student internship, I have a feeling, or even certainty, that the phenomenon of pretence in education of people with profound intellectual and multiple disabilities is still present and requires in-depth research exploration.

${ }^{6}$ In the context of this mechanism, we should remember about our language and, above all, about its "non-transparent aspects". "People are often unaware of the ideological load of certain ways of using language and the underlying power relations" (Fairclough, Wodak, 2006, vol. 2: 1047; cf. Klemperer, 1992; Kopec, 2013: 155).

7 Of course, we must not forget about the impact of the phenomena that occur on the level of macro- and microsystem. These are primarily legal acts established on the level of macrosystem and regulating education of a person with profound intellectual and multiple disability, and above all, the Regulation of the Minister of National Education of $23^{\text {rd }}$ April 2013 on the conditions and manner of organizing remedial classes for children and adolescents with profound intellectual disability (Journal of Laws 2013, item 529). After in-depth analysis of the acts, the inconsistencies with respect to education of people with profound intellectual and multiple disabilities were found which facilitate the phenomenon of pretence on the level of microsystem. These are, among others: 1) an introduction of the term: remedial classes, instead of a lesson, understood as a compulsory educational offer for a person with profound intellectual disability; 2) granting a person with profound intellectual disability the status of a participant in remedial classes, and not a student, despite the necessity to provide compulsory education; 3 ) the lack of core curriculum, the scope of teaching and upbringing content, as well as not defined forms of classes (Kopec, 2013: 150-169). 
paradigm and the associated bioecological theory of development by Urie Bronfenbrenner (Bronfenbrenner, 1979; Bronfenbrenner, Moris, 1998; Schalock et al., 2010: 17-18; Schalock et al., 2010: 176).

A visible sign of pretence on the level of microsystem is the phenomenon of "educational void" 8 which occurs during remedial classes. This results from the fact that the time, which in principle should be distributed in such a way that it allows for:

- firstly: the transfer of knowledge to a person with profound intellectual and multiple disability (after all, remedial classes are part of the education system),

- secondly: the support of the development of a person with profound intellectual disability,

is not used to expand knowledge and support development, but is irretrievably lost (cf. Kwiecinski, 1995: 96-122). We should remember that for a student with profound intellectual and multiple disability, whose health condition causes frequent absenteeism from school, situations in which school time is irretrievably wasted raise serious concern and opposition.

Therefore, it is justified to ask for exemplification of the phenomenon of "educational void" observed during remedial classes. As I have already mentioned, due to numerous comorbidities and somatic diseases, a student ${ }^{9}$ with profound intellectual and multiple disability is a very demanding recipient of the educational offer, and therefore his/her mental state and current psychophysical resources must be taken into account. In relation to education of students with profound intellectual and multiple disabilities, Weiß indicates a specific triad of interactions that must appear in this context (2012, cit. Zentel, 2015). These include: transfer of knowledge, therapy and $\operatorname{care}^{10}$ (2012, cit. Zentel, 2015). Bearing in mind this triad (transfer of knowledge, therapy, care), I will make an attempt to present the signs of phenomenon of "educational void" in the areas distinguished by Weiß during student's all-day stay at school ${ }^{11}$ (cf. Zentel, 2015).

8 The term that appeared in the statement of one of my subjects - in vivo code (cf. Charmaz, 2009: 76-79). Describing a similar phenomenon in education of people with intellectual disabilities, Zentel uses the term "void" (in German: die Lücke) (2015).

9 I intentionally omit the term "participant" recommended by the regulation, and use the term “student” („Journal of Laws” 2013, item 529).

${ }^{10}$ In German, Unterricht, Therapie Pflege (Weiß, 2012, cit. Zentel, 2015).

${ }_{11}$ Analyzing the educational reality of German students with profound intellectual and multiple disabilities, Zentel identifies void (the phenomenon of "educational void") during: a lesson and/or classes, all-day and all-year stay at school, and in the implementation of specific educational content that should be common to all students. The criteria distinguished by the researcher apply to inclusive 


\section{The signs of the phenomenon of "educational void" in the area of care}

The signs of the phenomenon of "educational void" in the area of care (i.e. primarily eating a meal, toilet activities) during remedial classes can be analyzed in two contexts. The first context involves nursing activities as such; in the second context, nursing activities become a "core" of remedial classes, unfortunately at the expense of educational activities (transfer of knowledge) and therapeutic activities, which should also appear in the offer of remedial classes. I will discuss each of the activities, referring to the empirical material collected in the research, analyzed from the perspective of the research subject (Kopec, 2013: 227-247).

In the area of care, the phenomenon of "educational void" is usually caused by the prolonged duration of nursing activities, which always triggers a "time domino effect" reflected throughout the school day of the subject. From the perspective of the subjects, prolonged nursing activities always meant wasting time, with students unproductively waiting for their turn in nursing activities or for all participants of remedial classes to finish their nursing activities. During a one-time care activity, the waiting time ranged from 10 to 30 minutes (Kopec, 2013: 230-240). Given the fact that the period of school stay of a student with profound intellectual multiple disability is usually four hours a day (cf. „Journal of Laws” 2013, item 529, $₫ 10$ ) and that nursing activities are repeated, the waste of time is indeed significant. It is even more frustrating when we realize its obvious impact on shortening and/or completely skipping educational and therapeutic activities during the school stay of a student with profound intellectual and multiple disability. This way, nursing activities begin to prevail throughout the entire stay at school and, as I have already mentioned, become the axis around which remedial classes are organized. The "celebration of nursing activities" is undoubtedly favoured by stereotypical thinking about a student with profound intellectual and multiple disability as about the "object" of nursing interactions due to disorders coexisting with profound intellectual disability ${ }^{12}$. I fully agree with the statement that nursing activities are very important in the work with a student with profound intellectual and multiple dis-

\footnotetext{
education, i.e. when a student with profound intellectual and multiple disability attends a general school (2015, cf. Bauersfeld, 2015: 43-59).

${ }^{12}$ In the presentation speech entitled: Standards of care, education and therapy for people with profound intellectual and multiple disabilities, at the conference on the subjectivity of people with profound intellectual and multiple disabilities in Poznan in 2019, Maciej Baraniewicz quoted the opinions of teachers working with students with PMID on the offer provided to students within remedial classes. The offer related to education and care was predominant.
} 
ability and that they can be used for educational and therapeutic purposes (cf. Fröhlich, 1991; Finnie, 1994; Fröhlich, 1998, 2015). However, they cannot become the only activities offered to students during remedial classes. Nevertheless, I am aware that, compared to educational and therapeutic activities, nursing activities are the easiest option possible to offer to a student with profound intellectual and multiple disability.

\section{The signs of the phenomenon of "educational void" in the area of therapy}

Therapeutic classes ${ }^{13}$ are the second, after care, type of classes that predominates the educational offer (I am not sure if it can be called that) for a student with deep intellectual and multiple disabilities ${ }^{14}$ as part of remedial classes in the Polish education system. In the context of time distribution, the phenomenon of "educational void" can be analyzed in two dimensions:

- institutional, taking into account the perspective of the institution where remedial classes are run,

- individual, taking into account the perspective of a student with deep intellectual and multiple disability (Kopec, 2013: 244-247).

We should remember that the analysis of the time devoted to therapeutic classes in the institutional dimension merely shows how much time the institution, such as school or other educational institution responsible for organizing remedial classes assigned to these activities. The duration of the entire block of remedial classes is precisely defined by the ministerial regulation on the implementation of remedial classes („Journal of Laws” 2013, item 526, \$10). However, the actual time devoted to therapeutic activities in the strict sense will depend on the schedule of remedial classes at a given school/educational institution and the organizational form of the activities (institutional dimension) (cf. Kwiecinski, 1995: 96-122; Kopec, 2013: 246). Therefore, in order to determine whether the time devoted to therapeutic activities during remedial classes was actually used in such a way as to support the development of a student with profound intellectual and multiple disability, it is not enough just to analyze the weekly or daily schedule of remedi-

${ }_{13}$ These include the following types of activities: basal stimulation, snoezellen, sensory integration method, the M. \& Ch. Knill method, the method of developing movement by Weronika Sherborne.

${ }^{14}$ Lamers emphasizes that the more severe the level of intellectual disability, the less knowledge is transferred to the benefit of care and therapy (2000). 
al classes. It is because the institutional dimension should be compare with the individual dimension (i.e. analysis of the time of classes from the perspective of a student with profound intellectual and multiple disability), and this (the individual dimension) will be an indicator of the quality of time spent at school. Hence, the information that, for example, sensory stimulation classes ${ }^{15}$ last 45 minutes means that this is the time of sensory stimulation dedicated to the entire remedial group. In the individual dimension, i.e. from the perspective of a student with profound intellectual and multiple disability, "these classes will not last $45 \mathrm{~min}$ utes, as suggested by the schedule, but only as much time as the teacher devotes to a given student; the time must be divided into all participants of remedial classes, i.e. a maximum of four" ${ }^{16}$ (see „Journal of Laws” 2013, § 9.2). Therefore, it will be only about 11,3 minutes, not 45 minutes for a person with profound intellectual and multiple disability (Kopec, 2013: 246).

For therapeutic activities implemented during remedial classes, two aspects are particularly important, i.e. taking into account the real needs of a student with profound intellectual and multiple disability as well as knowledge of the teacher. Personally, I very much resonate with Yoga Berrara's motto: "if you don't know where you are going, you have to be very careful because you may not get there" (2015: 163). The lack of a clear, defined goal of the classes and the competent teacher facilitate the phenomenon of "educational void". One of the subjects draws attention to the importance of knowledge and the pitiful consequences of teacher's ignorance. "They lack 'professional knowledge' that would validate their actions, they should know why they provide a certain educational offer to a given child. Sometimes it is scary that teachers cannot answer these simple questions. They use methods because they know them or know a bit about them, but they don't know whether it is really good for a given child [P23]"(Kopec, 2013: 288-289).

\section{The signs of the phenomenon of "educational void" in the area of knowledge transfer}

As I have already mentioned, a description of the phenomenon of pretence in the educational reality of a person with profound intellectual and multiple disability was not the purpose of my research project. I have accidentally discovered the ex-

\footnotetext{
15 The name of the classes comes from the weekly schedule analyzed during the research project.

${ }^{16}$ A relationship was found between the legal acts established on the level of macrosystem and the phenomena observed on the level of microsystem. It is legitimate to formulate a thesis that legal acts facilitate the phenomenon of "educational void" on the level of microsystem.
} 
istence of this phenomenon when describing the educational reality of a disabled person. The analysis of the research material inclines me to admit that in the area of transferring knowledge during remedial classes the term "educational void" is the most adequate and accurate expression. It can be characterized as the complete lack of introducing educational content during remedial classes (cf. Lamers, 2000; Baraniewicz, 2019). Referring to the Weiß educational triad (cit. Zentel, 2015), we can conclude that during remedial classes the areas of therapy and care are filled with content (and usually just these two areas!). The phenomenon of "educational void" confronts special educators with the lack of educational content in the work with a person with deep intellectual and multiple disability. At the same time, this situation implies important questions about education in the strict sense offered to a disabled PERSON; the form of which should have the educational content to be useful from this PERSON's perspective. The existence of the phenomenon of "educational void" proves discrimination of a person with profound intellectual and multiple disability in the Polish education system ${ }^{17}$.

\section{Final considerations}

The question arises where to seek determinants of the phenomenon of "educational void" during remedial classes. In my opinion, two main categories can be distinguished: institutional and personal (Kopec, 2013: 287). Institutional factors responsible for the phenomenon of "educational void" can be considered on two levels: macro- and microsystem. On the level of macrosystem, these include the Regulation of the Minister of National Education on the principles of organizing remedial classes for children and adolescents with profound disability of $23^{\text {rd }}$ April 2013 („Journal of Laws”, item 529). On the level of microsystem, there is a weekly schedule of remedial classes in a school and/or educational institution. It should contain details of all activities ${ }^{18}$ offered during the day to students with profound intellectual and multiple disabilities. Personal factors responsible for the phenomenon of "educational void" are related to people working with participants of remedial classes. In terms of content, structure and organization, the form of

\footnotetext{
17 The concept of two German special educators Wolfgang Lamers and Norbert Heinen - education with ForMat (2000) turns out to be helpful in filling the "educational void".

${ }_{18}$ A daily schedule should also include the time necessary for students to reach the classroom; the exact time of care and rest.
} 
remedial classes will depend on the teacher's responsiveness, mentalizing skills and knowledge (Kopec, 2013: 287-288) ${ }^{19}$.

The complete elimination of the phenomenon of pretence from education of people with profound intellectual disability is an illusion - as it will always be connected with the processes that occur on the level of chronosystem, to a greater or lesser extent entangled in the political system of the state on the level of macrosystem. However, this does not exempt teachers working with students with profound intellectual disabilities from the obligation to constantly demystify the phenomenon of pretence. It is a task for every special educator - practitioner and theoretician, to prevent and identify the phenomenon of pretence in education. On the level of macrosystem, it is care for clarity and precision of legal acts, as well as for using non-stigmatizing language. The acts should put emphasis on the need to equally include the subject of care, therapy and education in remedial classes. On the level of microsystem, the actions primarily include:

- creating a very detailed schedule (weekly, daily) for students with profound intellectual and multiple disabilities taking into account their actual needs and resources, including care, therapy and education;

- working in a relationship and paying attention to protective, stable relationships with the involvement of chief institutions and family support in order to ensure safety and protection (Greenspan, Wieder, 2014: 261);

- identifying by a special educator the areas favouring the phenomenon of pretence in accordance with the statement: "There will be change in the world and let it begin with you" (Powell, Cooper, Hoffman, Marvin, 2015: 260).

\section{Bibliography}

Baraniewicz M. (2019), Standards of care, education and therapy of people with profound intellectual and multiple disabilities. Paper presented at the Conference on the subjectivity of people with profound intellectual and multiple disabilities, Poznan, $29^{\text {th }}$ November.

Bauersfeld S. (2015), Educational content and profound disability - the process of planning classes, in: Baseline education. Teaching and therapy of children with profound disabilities, ed. A. Fröhlich, Sopot, pp. 43-61.

Bourdieu P. (2006), Pascal meditations, Warsaw.

Bronfenbrenner U. (1979), The ecology of human development, Harvard.

${ }^{19}$ Of course, a student with profound intellectual and multiple disability will also have an impact on the course of remedial classes, but it is a special educator always fully responsible for their course. 
Bronfenbrenner U., Morris P.A. (1998), The ecology of developmental processes, in: Handbook of child psychology, vol. 1: Theoretical models of human development, ed. R.M. Lerner, New York, pp. 993-1028.

Charmaz K. (2009), The grounded theory. A practical guide to qualitative analysis, trans. B. Komorowska, Warsaw.

DSM-5 (2016), Diagnostic criteria from DSM-5. Desk Reference, Wroclaw.

Dudzikowa M. (2004), The myth about school as a place of comprehensive development of a student. Entnopedagogical essays, Krakow.

Dudzikowa M. (2013), Pretend activities in education as an urgent problem. Introduction to the book in: Perpetrators and/or victims of pretend activities in school education, ed. K. Knasiecka-Falbierska, Krakow.

Durkheim E. (2006), Suicide. A study in sociology, Warsaw.

Fairclough N., Wodak R. (2006), Critical discourse analysis, trans. A. Ostolski, in: Contemporary sociological theories, vol. 2, eds. A. Jasinska-Kania, L.M. Nijakowski, J. Szacki, M. Ziolkowski, Warsaw, pp. 1047-1061.

Fröhlich A. (1998), Stimulation from scratch, trans. Z. Bialek, L. Czarkowska, A. Firkowska-Mankiewicz, Warsaw.

Fröhlich A. (ed.) (2015), Baseline education. Teaching and therapy of children with profound disability, Sopot.

Greenspan I.S., Wieder S. (2014), Reach a child with autism. How to help children establish relationships, communicate and think. Floor time method, trans. D. Braithwaite, Krakow.

Heinen N., Lamers W. (2006), Bildung mit ForMat. Impulse für enie veränderte Unterrichtspraxis mit Schülerinnen und Schülern mit (schwerer) Behinderung, in: Basale Stimulation. Kritsch-konstruktiv, eds. L. Desiree, W. Lamers, N. Heinen, Düsseldorf, pp. 141-205.

Klemperer V. (1992), Philologist's notebook, trans. M. Stroinska, Toronto.

Kopec D. (2013), The (non)educational reality of a person with profound intellectual disability. Collective instrumental case study, Poznan.

Krause A., Zyta A., Nosarzewska S. (2010), Normalization of the social environment of people with intellectual disability, Torun.

Kubinowski D. (2010), Qualitative pedagogical research. Philosophy. Methodology. Evaluation, Lublin.

Kwiecinski Z. (1995), Work at school as an illusion, in: Sociopathology of education, ed. Z. Kwiecinski, Olecko, pp. 96-122.

Lamers W. (2000), Goethe und Matisse für Menschen mit einer schwerer Behinderung, in: Geistigbehindertenpädagogik als Begegnung, eds. N. Heinen, W. Lamers, Düsseldorf, pp. 177-208.

Parys K. (2014), The phenomenon of pretence in the education system of students with disabilities an attempt to identify and propose solutions, „Interdisciplinary Contexts of Special Education”, no. 4, pp. 29-56.

Powel B., Cooper G., Hoffman K., Marvin B. (2015), The circle of confidence. Attachment strengthening intervention in early parent-child relationships, trans. R. Andruszko, Krakow.

Rubacha K. (2008), Methodology of education research, Warsaw.

Schalock R.L., Borhwick-Duffy S.A., Luckasson R. et al. (2010), Intellectual Disability. Definition, Classification and Systems of Supports. The AAIDD Ad Hoc Committee on Terminology and Classification, $11^{\text {th }}$ Edition. AAIDD, Washington.

Stake R.E. (2009), Qualitative case study, trans. M. Salkowska, in: Qualitative research methodology, vol. 1, eds. N.K Denzin, Y.S. Lincoln, Warsaw, pp. 623-655. 
Yin R.K. (2015), Case study in research. Design and methods, Krakow.

Zakrzewska-Manetrys M. (2010), The mentally handicapped. Beyond humanity, Warsaw.

Zentel P. (2015), Schülerinnen und Schüler mit schwerer und mehrfacher Behinderung in der Inklusion. Paper presented at the scientific seminar: Person with profound intellectual disability in the education system, $2^{\text {nd }}$ December, Poznan.

\section{Legal acts}

„Journal of Laws” 1997, no. 14, item 76, Regulation of the Minister of National Education of $30^{\text {th }}$ January 1997 on the principles of organizing remedial classes for children and adolescents with profound intellectual disabilities.

„Journal of Laws” 2012, item 1169, Convention on the Rights of Persons with Disabilities.

„Journal of Laws" 2013, item 529, Regulation of the Minister of National Education of $23^{\text {rd }}$ April 2013 on the conditions and manner of organizing remedial classes for children and adolescents with profound intellectual disabilities. 
